\title{
Editorial: Impact of Deep Oceanic Processes on Circulation and Climate Variability: Examples From the Mediterranean Sea and the Global Ocean
}

\author{
Nadia Lo Bue ${ }^{1 *}$, Vincenzo Artale ${ }^{2}$ and Katrin Schroeder ${ }^{3}$ \\ ${ }^{1}$ Istituto Nazionale di Geofisica e Vulcanologia (INGV), Rome, Italy, ${ }^{2}$ National Research Council (CNR), Rome, Italy, ${ }^{3}$ Institute \\ of Marine Science, National Research Council (CNR), Rome, Italy
}

Keywords: abyssal ocean, deep dynamic process, climate variability, mixing process, Mediterranean Sea, global ocean, multidisciplinary approach

\section{Editorial on the Research Topic}

Impact of Deep Oceanic Processes on Circulation and Climate Variability: Examples From the Mediterranean Sea and the Global Ocean

\section{INTRODUCTION AND SUMMARY}

OPEN ACCESS

Edited and reviewed by: Frédéric Cyr,

Fisheries and Oceans, Canada

*Correspondence:

Nadia Lo Bue

nadia.lobue@ingv.it

Specialty section:

This article was submitted to

Physical Oceanography,

a section of the journal

Frontiers in Marine Science

Received: 25 October 2021 Accepted: 22 November 2021 Published: 10 December 2021

Citation:

Lo Bue N, Artale V and Schroeder K

(2021) Editorial: Impact of Deep

Oceanic Processes on Circulation and Climate Variability: Examples From the

Mediterranean Sea and the Global Ocean. Front. Mar. Sci. 8:801479,

doi: 10.3389/fmars.2021.801479
The ocean is a crucial component of the Earth's climate system. Storing heat and carbon, the ocean stabilizes global climate, nurtures biodiversity, and directly supports human well-being through food and energy resources. Today it is well-known that ocean warming is the result of an interplay of many complex processes that, in spite of the key role in the Earth's energy budget, are still far from being fully understood. More than $93 \%$ of the heating since the 1970 s due to the greenhouse effect and other human activities has been absorbed by the ocean (Rhein et al., 2013). The intake of heat and $\mathrm{CO}_{2}$ in the ocean's surface is redistributed throughout the ocean depths by the overturning circulation. Exchange across the ocean's turbulent surface boundary layer can happen rapidly, in hours or days, and significant exchange of water between the boundary layer and the stratified main thermocline occurs over timescales of years to decades. Deep water takes many decades to millennia to return to the surface, acting as long-term storage for heat and $\mathrm{CO}_{2}$ and thereby mitigating the short-term impacts of climate change. The understanding of mechanisms and rates that control the bottom flows is essential to quantify re-transfer toward the upper layers of the energy stored at the bottom layers. These processes are significantly affecting the ocean system as a whole and could contribute to accelerating the rising climate trends (thermohaline circulation, sea-level rise, and ocean acidification).

The Research Topic about "Impact of Deep Oceanic Processes on Circulation and Climate Variability" happens during an exceptional time for ocean studies. In fact, the decade from 2021 to 2030, has been declared as the Decade of Ocean Science for Sustainable Development by the United Nations, aimed at providing a common framework to ensure that ocean science can fully support countries to achieve the 2030 Agenda for Sustainable Development. The Ocean Decade gives a "once in a lifetime" opportunity to create a new foundation across the science-policy interface to strengthen the management of our oceans and coasts for the benefit of humanity. 
This Research Topic aims at stressing the urgent need of improving knowledge about the impacts of key deep processes, for better contributing in the assessment of climate variability and change. For a long time, classical theories about the abyssal ocean (Stommel and Arons, 1960; Munk, 1966) supported the general idea that ocean deep circulation was characterized by quasistationary motions, excluding the study of deep processes from the mechanisms that can affect global circulation and climate variability. The underestimation of the abyssal ocean variability has continued to persist for decades (Bagnell and De Vries, 2021), due also to the difficulty to obtain reliable observations below 2,000 m depth, as Artale et al. (2018) demonstrated for the Mediterranean Sea. The awareness of the unsteady state of the deep ocean is a fairly recent achievement. These recent assumptions (Ferrari et al., 2016; MacKinnon et al., 2017; McDougall and Ferrari, 2017; Holmes et al., 2018; Polzin and McDougall, 2021) are shedding light on the rising need to fully understand the mechanisms that can induce instability of the deep layers with a particular look at the role that seafloor roughness and shape have in triggering bottom mixing processes (de Lavergne et al., 2016; Naveira Garabato et al., 2019; Spingys et al., 2021). Observational datasets over many decades are required to document, understand, and predict the climate system as a whole. This is key to explain the role of the deep ocean as an energy reservoir, and how deep processes can redistribute such energy affecting ocean circulation and, afterwards, giving consequences on the future climate. Also, it represents an essential requirement to detect and attribute changes driven by human activities and to predict how the climate system will likely behave in the future.

The Mediterranean Sea, due to its peculiar ocean circulation characteristics, can be considered, among all marginal seas, a suitable laboratory for investigating almost all oceanic physical mechanisms of global interest, such as deep water formation/deep convection, mixing processes along the entire water column (including bottom mixing), strait dynamics, advective-convective feedbacks driving the ocean variability, and abyssal dynamic internal exchange mechanisms (Ferron et al., 2017; Vladoiu et al., 2019). All these studies are facilitated in the Mediterranean Sea, thanks to its easy accessibility, to its mild climate and weaker storms, and also to the scales of variability (in time and space) that are shorter compared to the global ocean: here the typical Rossby radius and/or the size and time of variability of mesoscale gyres are one order of magnitude less compared to those of the global ocean.

On the whole, to understand past and future climate changes, the characterization of the still unexplored deep dynamics aims to provide crucial results to support new interpretations of the paleo circulation and of those processes that have influenced ventilation and water masses overturning in the past. These new insights will also be essential for leading, in the near future, new tailored parameterizations for new generation climate numerical models taking into account adequately the dynamics below 2,000 m depth.

\section{CONTRIBUTION TO THE FIELD, GAPS, AND PERSPECTIVES}

This article collection was conceived in the framework of MedClivar (http://www.medclivar.eu/), a scientific network to promote better cooperation among different scientific disciplines, to develop a multidisciplinary vision of the evolution of the Mediterranean climate. Extending this concept also to the global ocean, the aim is to investigate the impacts associated with climate evolution, and to provide knowledge through studies that integrate all components of the climate on time scales ranging from paleo-reconstructions to future climate scenarios for contributing in the development of new adaptation strategies.

As assumed by von Schuckmann et al. (2018), the improvement of our understanding of the climate system also passes through the monitoring of heat content, including that below 2,000 $\mathrm{m}$. However, the needs for and uses of deep ocean data extend well-beyond closing the heat budget in the global ocean as well as in the Mediterranean Sea. Deep ocean data is needed to initialize and constrain ocean models and improve their representation of mixing of heat downwards/upwards within the deep layers.

In this Research Topic, several studies addressing the study of deep processes through in situ observations and modeling spanning over different geographic areas have been collected. The collected papers get a varied overview of methodologies today used to investigate the impact that deep processes can have on climate variability, pointing out the importance of multidisciplinarity in addressing this kind of issue. They focus on the Mediterranean as a whole (Sampatakaki et al.; Amitai et al.; Li and Tanhua; Bouzaiene et al.), or just regions of the Western (Durante et al.; Ferron et al.; the two works by Vargas-Yáñez et al. (2021); García-Lafuente et al.) or Eastern (Mihanović et al.; Menna et al.; Sisma-Ventura et al.; Cardin et al.) Mediterranean Sea. But there are also examples of deep oceanic processes coming from other areas of the global ocean, i.e., the Western Pacific Ocean (Wang et al.), the Southern Ocean (Mizuta et al.), and the Japan Sea (Shin et al.). This collection also provides a variety of approaches to investigate the oceanic processes. The lagrangian approach, which is typically adopted for the surface ocean (Menna et al.; Bouzaiene et al.), with inferences for the deeper layers, or in combination with a multiplatform and integrated model experiment (such as in Mihanović et al.), has potential to be applied to deeper layers as well, with the more and more expanding (deep) Argo network. Other papers rely on eulerian data (from moorings and buoys, Wang et al.; Mizuta et al.; García-Lafuente et al.; Shin et al.) or CTD/rosette data collected by Research Vessels (Durante et al.; Ferron et al.; Li and Tanhua; the two works by Vargas-Yáñez et al. (2020); Sisma-Ventura et al.) or both (Cardin et al.). Purely modeling studies are also represented, see for instance (Amitai et al.; Sampatakaki et al.), the latter one being a paleoceanographic application.

Although the topic was addressing deep ocean processes in a broad geographical sense, it is worth noting that most of the papers focused on the Mediterranean area, confirming this area 
as most accessible for studying such kinds of topics and many other fundamental oceanographic processes.

Overall, the papers in this collection have evidenced that observations in the deep ocean, both in the Mediterranean Sea and in the open ocean, are still too sparse and fragmentary and that a huge gap still exists between modeling and observational approaches both in the physical and biochemical field. Especially for this latter, the lack of data in the deep ocean is due not only to the big challenge in observation, but also to the sensor technology, which is still not fully reliable for this extreme environment (Bindoff et al., 2019).

The existing gaps highlight how much the integrated and multidisciplinary approach in the study of deep ocean processes is now an urgent question, both for the knowledge improvement and for the efficient streamlining of the existing observational infrastructures such as EMSO and Deep-Argo (Gasparin et al., 2020; Lo Bue et al., 2021). Besides, due to its intrinsic characteristics and considering its short-scale variability (Malanotte-Rizzoli et al., 2014), the Mediterranean area results in a suitable area for developing

\section{REFERENCES}

Artale, V., Falcini, F., Marullo, S., Bensi, M., Kokoszka, F., Iudicone, D., et al. (2018). Linking mixing processes and climate variability to the heat content distribution of the Eastern Mediterranean abyss. Sci. Rep. 8:11317. doi: 10.1038/s41598-018-29343-4

Bagnell, A., and De Vries, T. (2021). 20th century cooling of the deep ocean contributed to delayed acceleration of Earth's energy imbalance. Nat. Commun. 12:4604. doi: 10.1038/s41467-021-24472-3

Bindoff, N. L., Cheung, W. W. L., Kairo, J. G., Arístegui, J., Guinder, V. A., Hallberg, R., et al. (2019). "Changing ocean, marine ecosystems, and dependent communities," in IPCC Special Report on the Ocean and Cryosphere in a Changing Climate, eds H.-O. Pörtner, D. C. Roberts, V. Masson-Delmotte, P. Zhai, M. Tignor, E. Poloczanska, K. Mintenbeck, A. Alegría, M. Nicolai, A. Okem, J. Petzold, B. Rama, and N. M. Weyer.

de Lavergne, C., Madec, G., Le Sommer, J., Nurser, G. A. J., and Naveira Garabato, A. C. (2016). On the consumption of Antarctic Bottom Water in the abyssal ocean. J. Phys. Oceanogr. 46, 635-661. doi: 10.1175/JPO-D-14-0201.1

Ferrari, R., Mashayek, A., McDougall, T. J., Nikurashin, M., and Campin, J. M. (2016). Turning ocean mixing upside down. J. Phys. Oceanogr. 46, 2239-2261. doi: 10.1175/JPO-D-15-0244.1

Ferron, B., Bouruet Aubertot, P., Cuypers, Y., Schroeder, K., and Borghini, M. (2017). How important are diapycnal mixing and geothermal heating for the deep circulation of the Western Mediterranean? Geophys. Res. Lett. 44, 7845-7854. doi: 10.1002/2017GL074169

Gasparin, F., Hamon, M., Rémy, E., and Le Traon, P.-Y. (2020). How deep argo will improve the deep ocean in an ocean reanalysis. J. Clim. 33, 77-94. doi: 10.1175/JCLI-D-19-0208.1

Holmes, R. M., de Lavergne, C., and McDougall, T. J. (2018). Ridges, seamounts, troughs, and bowls: topographic control of the dianeutral circulation in the abyssal ocean. J. Phys. Oceanogr. 48, 861-882. doi: 10.1175/JPO-D-17-0141.1

Lo Bue, N., Best, M. M. R., Embriaco, D., Abeysirigunawardena, D., Beranzoli, L., Dewey, R. K., et al. (2021). The importance of marine research infrastructures in capturing processes and impacts of extreme events. Front. Mar. Sci. 8:626668. doi: $10.3389 /$ fmars.2021.626668

MacKinnon, J. A., Zhao, Z., Whalen, C. B., Waterhouse, A. F., Trossman, D. S., Sun, O. M., et al. (2017). Climate process team on internal wave-driven ocean mixing. Bull. Am. Meteorol. Soc. 98, 2429-2454. doi: 10.1175/BAMS-D-16-0030.1 new integrated strategies able to link theory, observations, and implementation of new numerical models in the near future.

\section{AUTHOR CONTRIBUTIONS}

All the authors listed have made substantial, direct, and intellectual contributions to the work. NLB designed the structure of this editorial, contributed to its drafting, and synthesized the contributions received and made extensive editing. VA participated in the document design, he provided substantial contributions and suggestions throughout the document. KS participated in the document design, contributed to the drafting of the overall manuscript, and helped with its revision. All authors approved its publication.

\section{ACKNOWLEDGMENTS}

We thank all authors, reviewers, and editors that have contributed to this Research Topic and the MedClivar community to endorse and support it.

Malanotte-Rizzoli, P., Artale, V., Borzelli-Eusebi, G. L., Brenner, S., Crise, A., Gacic, M., et al. (2014). Physical forcing and physical/biochemical variability of the Mediterranean Sea: a review of unresolved issues and directions for future research. Ocean Sci. 10, 281-322. doi: 10.5194/os-10-281-2014, 2014

McDougall, T. J., and Ferrari, R. (2017). Abyssal upwelling and downwelling driven by near-boundary mixing. J. Phys. Oceanogr. 47, 261-283. doi: 10.1175/JPO-D-16-0082.1

Munk, W. (1966). Abyssal recipes. Deep Sea Res. Oceanogr. Abstr. 13, 707-730. doi: 10.1016/0011-74716690602-4

Naveira Garabato, A. C., Frajka-Williams, E. E., Spingys, C. P., Legg, S., Polzin, K. L., Forryan, A., et al. (2019). Rapid mixing and exchange of deep-ocean waters in an abyssal boundary current. Proc. Natl. Acad. Sci. U.S.A. 116, 13233-13238. doi: 10.1073/pnas. 1904087116

Polzin, K. L., and McDougall, T. J. (2021). “Chapter 7: Mixing at the ocean's bottom boundary," in Ocean Mixing, eds M. Meredith and A. N. Garabato (Elsevier), 145-180. doi: 10.1016/B978-0-12-821512-8.00014-1

Rhein, M., Rintoul, S. R., Aoki, S., Campos, E., Chambers, D., Feely, R. A., et al. (2013). "Observations: ocean," in Climate Change 2013: The Physical Science Basis. Contribution of Working Group I to the Fifth Assessment Report of the Intergovernmental Panel on Climate Change, eds T. F. Stocker, D. Qin, G.- K., Plattner, M. Tignor, S. K. Allen, J. Boschung, A. Nauels, Y. Xia, V. Bex, and P. M. Midgley (Cambridge; New York, NY: Cambridge University Press), 255-317.

Spingys, C. P., Naveira Garabato, A. C., Legg, S., Polzin, K. L., Povl Abrahamsen, E., Buckingham, C. E., et al. (2021). Mixing and transformation in a deep western boundary current: a case study. J. Phys. Oceanogr. 51, 1205-1222. doi: 10.1175/JPO-D-20-0132.1

Stommel, H., and Arons, A. B. (1960). On the abyssal circulation of the world ocean-II. An idealized model of the circulation pattern and amplitude in oceanic basins. Deep Sea Res. 6, 217-233.

Vargas-Yáñez, M., Juza, M., Balbín, R., Velez-Belchí, P., García-Martínez, M. C., Moya, F. et al. (2020). Climatological hydrographic properties and water mass transports in the balearic channels from repeated observations over 1996-2019. Front. Mar. Sci. 7:568602. doi: 10.3389/fmars.2020.568602

Vargas-Yáñez, M., Juza, M., García-Martínez, M. C., Moya, F., Balbín, R., Ballesteros, E., et al. (2021). Long-term changes in the water mass properties in the balearic channels over the period 1996-2019. Front. Mar. Sci. 8:640535. doi: 10.3389/fmars.2021.640535

Vladoiu, A., Bouruet-Aubertot, P., Cuypers, Y., Ferron, B., Schroeder, K., Borghini, M., et al. (2019). Mixing efficiency from microstructure measurements 
in the Sicily Channel. Ocean Dyn. 69, 787-807. doi: 10.1007/s10236-01901274-2

von Schuckmann, K., Le Traon, P.-Y., Smith, N., Pascual, A., Brasseur, P., Fennel, K., et al. (2018). Copernicus marine service ocean state report. J. Oper. Oceanogr. 11, S1-S142. doi: 10.1080/1755876X.2018.1489208

Conflict of Interest: The authors declare that the research was conducted in the absence of any commercial or financial relationships that could be construed as a potential conflict of interest.

Publisher's Note: All claims expressed in this article are solely those of the authors and do not necessarily represent those of their affiliated organizations, or those of the publisher, the editors and the reviewers. Any product that may be evaluated in this article, or claim that may be made by its manufacturer, is not guaranteed or endorsed by the publisher.

Copyright (C) 2021 Lo Bue, Artale and Schroeder. This is an open-access article distributed under the terms of the Creative Commons Attribution License (CC BY). The use, distribution or reproduction in other forums is permitted, provided the original author(s) and the copyright owner(s) are credited and that the original publication in this journal is cited, in accordance with accepted academic practice. No use, distribution or reproduction is permitted which does not comply with these terms. 